\title{
A Relationship between Operational Status of Equipment and Technical Proficiencies of Aeronautical Engineering Students: A Case Study
}

\author{
By Katherine Minarik ${ }^{*}$, Peng-Hao Wang $^{\dagger}$ \& \\ Sergey Dubikovsky
}

\begin{abstract}
All students in the Aeronautical Engineering Technology program of Purdue University's School of Aviation and Transportation Technology are required for graduation to complete a reciprocating engine overhaul course. This study examined the relationship between engine operational status and students' technical competencies after a semester of maintenance practice on the engine. The tests were administered by laboratory instructors to determine whether there was a difference with technical competency with students who serviced operational engines verses nonoperational engines. Competency tests in the study were modeled from the Federal Aviation Administration (FAA) requirements for the practical test questions from the Airframe and Powerplant Certificate $(A \& P)$ examination. The tests were formatted and measured based on the criteria outlined in the Federal Aviation Administration's Aviation Mechanic Powerplant Practical Test Standards (FAA-S-8081-28A).
\end{abstract}

Keywords: Aeronautical Engineering Technology, Aviation, Equipment, Hands-On Learning, Project-Based Learning.

\section{Introduction}

The aviation industry is currently experiencing unprecedented growth. Boeing's Pilot and Technician outlook for 2018-2037 projects that 754,000 new maintenance technicians will be needed to maintain the world's aircraft fleet. North America will experience the second largest demand for maintenance personnel by requiring at least 189,000 new maintenance technicians (Boeing 2018). As the market continues to become more competitive, companies will look for their workforce to be the competitive differentiator. Companies will be looking for professionals who already have the required skills and can be trained quickly to meet operational requirements.

Many industry professionals predict that the demand for maintenance technicians will surpass the supply as soon as 2022 in the United States (Prentice and Costanza 2017). Due to the expected rapid fleet growth in Asia, Prentice anticipates that the effects of the shortage will be seen much sooner in Asia. One of the leading causes for the shortage of maintenance technicians is due to the aging maintenance technician workforce. In the US, the median age of an aviation mechanic is 51 years old. Within the next decade, many of the

\footnotetext{
*Graduate Teching Assistant, Purdue University, USA.

${ }^{\dagger}$ Assistant Professor, Purdue University, USA.

*Associate Professor, Purdue University, USA.
} 
aging maintenance technicians will be eligible to retire. The United States government has recognized the upcoming critical shortage (Walsh 2018). Senators Jim Inhofe, Richard Bluementhal, Jerry Moran, and Maria Cantwell are all sponsoring the Aviation Maintenance Workforce Development Pilot Program. The Aviation Maintenance Workforce Development Pilot Program will financially support workforce development initiatives for students through scholarship programs, veteran transition programs and enhancing aviation technical education.

Purdue University's School of Aviation and Transportation Technology (SATT) in Indiana, United States of America, has been training future maintenance technicians in order to close the gap between supply and demand since the 1940s. The School of Aviation and Transportation Technology (SATT) at Purdue University prides itself for training career-ready emerging maintenance technicians for the aviation industry. However, the school offers more than just aviation maintenance certification. Students enrolled in the School of Aviation and Transportation Technology (SATT) can pursue a bachelor's or master's degree in Aviation Management, Aeronautical Engineering Technology (AET), Unmanned Aerial Systems, or Professional Flight Technology. The Aeronautical Engineering Technology degree program blends ABET, Inc. accredited engineering teachings and aviation maintenance practices to train a well-rounded aviation professional. Upon completion of the program and in addition to the bachelor degree) most Aeronautical Engineering Technology students are eligible to receive a 14 CFR Part 147 (Aviation Maintenance Technician Schools) training certificate and qualify to take the tests for the Federal Aviation Administration (FAA) Airframe and Powerplant Certificate (A\&P). As the needs of the industry continue to grow, the School of Aviation and Transportation Technology continues to increase enrollment of all programs to accommodate those needs.

Aeronautical Engineering Technology degree courses are structured with both lecture and laboratory periods. Lectures focus on teaching principles, major concepts, and engineering theory while laboratories serve as time for students to apply these concepts and gain competency through practical engineering and maintenance projects. Aeronautical Engineering Technology students spend hundreds of hours in laboratories throughout their degree studies to apply and practice maintenance concepts that were introduced to the students in lecture.

One required course for the Aeronautical Engineering Technology program is a specialized reciprocating engine overhaul course. In that course, students are taught engineering and maintenance concepts regarding inspection, troubleshooting, repair, and overhaul. The laboratory is set up in a hangar with reciprocating engines on engine stands. Some engines are operational while some are not due to the engine's intended educational purpose or the restriction of resources. Student groups are randomly assigned to engines and must complete overhaul tasks through structured project-based learning that includes receiving inspection, disassembly, cleaning, final inspection, and reassembly. At the end of the overhaul process, the operational engines ran to ensure that the overhaul process was done and met required standards. All students, regardless of engine 
assignment, have an opportunity to run an operational engine throughout the semester.

Through the years, it has been noted that students assigned to engines that are nonoperational seem to feel less pressure to perform the maintenance tasks correctly and thoroughly because at the end of the semester their engine is not expected to run again. This study hypothesizes those students that perform maintenance procedures on operational equipment perform work that is of higher technical competency because of the increased pressure of having to return the engine back to service. Students' work that is performed on nonoperational equipment is of lower technical competency because there is no pressure to have the equipment operational again. Therefore, the implications of operational equipment vs. nonoperational equipment are very large and impactful on students' maintenance training and education.

Understanding the implications of operational equipment with regards to student learning is very important and has implications on key financial decisions on whether to keep current equipment operational or look at alternative methods for student training.

\section{Literature Review}

Project-based learning is used in Engineering Technology curriculum and 14 CFR Part 147 training at Purdue University's School of Aviation and Transportation Technology, because of project-based learnings' benefits over other teaching methods being widely accepted and recognized. Traditional teaching methods create barriers that prevent students from optimizing the instruction with their prior knowledge. Some other barriers to learning that students might experience from traditional teaching methods can include lack of motivation and engagement (Robinson 2013). Robinson surmises that these barriers exist because the student might not understand the importance and relevancy to the work. Robinson outlines the methods to project-based learning. The most significant requirement of project-based learning is the implementation of complex, authentic tasks. Robinson defines this "complex, authentic tasks" as work that would be appealing to someone outside of the class. There are also other important criteria for successful project-based learning. These criteria include students deciding how to accomplish the project as well as collaboration in a team environment. Robinson states that each of these steps is equally important when planning project-based coursework. Allowing students to feel in control of their own work and being accountable for the results is essential with project-based learning.

Project-based learning is a tried and true learning method according to Shin (2018). Shin's students participate in project-based learning because they are able to use their own experiences to tackle the problems assigned to them. Shin also explored the connections between student motivation and cooperation when using project-based learning methods and found that project-based learning positively motivates students and also increases their levels of 
cooperation. Furthermore, Shin found that the students' perceptions of projectbased learning were positive.

The traditional educational methods of essay writing and memorization have been found to disrupt the creative process and natural conversations that occur between students and teachers when learning (Behizadeh 2014). Projectbased learning aims to fill the gap by getting students and instructors to interact more naturally. Behizadeh also mentions that in order to facilitate learning, teachers need to ask their students to draw upon prior knowledge. This method is called problem-posing education. Problem-posing education is the perfect lead into project-based learning. Problem-posing is at the center of projectbased learning. Students can create projects in order to solve problems and there is great benefit from problem-posing because learning through memorization and essay writing without project-based learning has proven to be less effective.

Rahman et al. (2017) explored the implications of project-based learning. The researchers found that 75 percent of students who utilized project-based learning in the study showed signs of problem-solving ability improvement. In addition, students who were taught through project-based learning showed improvement of their ethical character. The experimental class in the study showed a higher average improvement in proper ethics than the control class.

In addition to higher levels of cooperation and ethics, students are also able to develop professional skills when participating in a project-based learning curriculum. Johnson and Ulseth (2017) acknowledged the shift to emphasize professional competencies development by students. Then the authors also explored the experiences that the students have when professional competency skills are prioritized as learning outcomes for students in the courses. Johnson and Ulseth found that there is an increase in performance of professional competencies by students who participated in project-based learning over students who used traditional styles and methods. Students who participated in Johnson's and Ulseth's study were also able to better explain professional competency expectations with regards to the work place than the control group. This is reinforced by the student's exploration and reflection of professional identity within projects that cannot be reached through traditional methods of learning.

In order for instructors to implement project-based learning, there is a classical pedagogy to follow. Hwang et al. (2017) say that there should be 7 core stages to project-based learning. Only five stages are recognized currently. They are preparation, implementation, presentation, evaluation, and revision. The authors suggested that two additional stages be added because the current model lacks the ability to reach the learning outcomes of typical Capstone courses. Thus the new model should be preparation, conception, design, implementation, operation, evaluation, and revision. The old model lacks two features that build creative thinking skills and design process. They tested their new model on a capstone course and found that the students demonstrated significantly increased creativity skills and kept a more systematic record and analysis of all creativity tasks that were required for the capstone.

Unfortunately, developing curriculum for each of the stages of project-based learning is not the only barrier to implementation. An education institution's 
support is also very important for the success of project-based implementation within the curriculum. In Hong Kong project-based learning is being implemented feverishly (Lam et al. 2010). Lam explained this trend of sudden transition is because of the need to equip students with critical thinking and collaborative skills before graduation. The implementation process of projectbased learning in learning institutes is further explored by Lam. 182 secondarylevel teachers from Hong Kong were asked to complete a questionnaire about school support with regards to the transition as well as their own personal motivation towards implementing project-based learning. The results of the questionnaire stated that teachers were more motivated to implement projectbased learning when they felt that their school was supportive of them. This means that instructors will feel more compelled to undertake a large project such as redesigning the curriculum and teaching methods with institutional support.

As stated in the introduction, Purdue University's School of Aviation and Transportation Technology partakes in project-based teaching methods. These teaching methods go hand in hand with the Federal Aviation Administration's expected learning outcomes for an individual pursuing a Federal Aviation Administration's Airframe and Powerplant certificate. The Federal Aviation Administration provides guidelines for the certification of airframe and powerplant mechanics. In order to complete the certificate, candidates must pass written, oral and practical tests for general, airframe, and powerplant subjects. The experimentation for this study was developed referencing the Federal Aviation Administration document, FAA-S-8081-28A, the Aviation Mechanic Powerplant Practical Test Standards and keeping all FAA criteria and standards in mind. To collect research data, the FAA guidelines were chosen to evaluate students on practical projects because they are the minimum and baseline standards of competency within the aviation industry.

The FAA defines three performance levels that must be assessed during the practical test. Each performance level and the definitions of the level are listed below:

$\underline{\text { Level } 1}$ - Know basic facts and principles. Be able to find information and follow directions and written instructions. Locate methods, procedures, instructions, and reference material. Interpretation of information not required. No skill demonstration is required.

Level 2 - Know and understand principles, theories, and concepts. Be able to find and interpret maintenance data and information, and perform basic operations using the appropriate data, tools, and equipment. A high level of skill is not required.

Level 3 - Know, understand, and apply facts, principles, theories, and concepts. Understand how they relate to the total operation and maintenance of aircraft. Be able to make independent and accurate airworthiness judgments. Perform all skill operations to a return-to-service standard using appropriate data, tools, and equipment. Inspections are performed in 
accordance with acceptable or approved data. A fairly high skill level is required (FAA 2012).

Additionally, FAA-S-8081-28A defines satisfactory performance and unsatisfactory performance that the Designated Mechanic Examiner (DME) must use to assess candidates. Satisfactory performance is achieved if the applicant demonstrates the prescribed proficiency in the assigned elements in each subject area to the required standard. Applicants shall not be expected to memorize all mathematical formulas that may be required in the performance of various elements in this practical test standard. However, where relevant, applicants must be able to locate and apply necessary formulas to obtain correct solutions.

Unsatisfactory performance is diagnosed by the Designated Mechanic Examiner (DME) if the candidate does not meet the standards of any of the elements performed (knowledge or skill elements), failing the associated subject area, and thus failing the section of the practical test. Typical areas of unsatisfactory performance and grounds for disqualification include the following:

1. Any action or lack of action by the applicant that requires corrective intervention by the examiner for reasons of safety.

2. Failure to follow acceptable or approved maintenance procedures while performing skill (practical) projects.

3. Exceeding tolerances stated in the maintenance instructions

4. Failure to recognize improper procedures.

5. The inability to perform to a return to service standard where applicable

6. Inadequate knowledge in any of the subject areas.

"The inability to perform to a return to service standard where applicable" will be explored by testing students while using operational equipment and nonoperational equipment. Students will be assigned a practical project that they must demonstrate to an instructor. Competency of the student will be assessed based on the Federal Aviation Administration's criteria described above.

The practical project will be selected from the FAA subject testing outlined in Section IV - Powerplant Theory and Maintenance subsection A. Reciprocating Engines. The FAA requires that all applicants be able to exhibit knowledge in a wide variety of topics regarding reciprocating engine theory. The FAA also outlines skills to perform and what competency levels must be achieved by an applicant. Those objectives include demonstrating skill to perform engine overhaul concepts, inspection techniques, and other maintenance repairs.

\section{Methodology}

IRB process: This study participated in the Institutional Review Board (IRB) process. The IRB serves to protect human subjects participating in research studies 
(University of Pittsburgh 2018). This study complied with all criterion of the IRB that governed this research.

Participants: Students enrolled in the Advanced Reciprocating Engine Overhaul course were tested. There were a total of 32 students. The students were assigned into two groups by laboratory section. Students within the sections were divided into groups of eight. The students in each section were first tested on operational equipment and then retested on the nonoperational equipment. The other half of the students were tested first on nonoperational equipment and then tested again on operational equipment.

The students sampled came from a diverse background. As seen in Table 1, the majority of the students are ages 21-22 years old. The sample comprises mostly of seniors due to the course being offered later in the curriculum. Twenty-one of the students who were in the class started their college career at the School of Aviation and Transportation Technology instead of transferring or Change of Degree Objective (CODO) into the program. CODO is the official process for students to transfer to a different area of study. Eleven students who were in the class had transferred or CODO in from another programs. Out of the thirty-two students, twenty-eight students plan on pursuing a career in the aviation industry. Finally, all but three of the students are planning on eventually testing for their Federal Aviation Administration's Airframe and Powerplant certificate.

Table 1. Student Demographics

\begin{tabular}{|l|l|l|l|l|}
\hline \multirow{2}{*}{ Age } & $19-20$ & $21-22$ & $23-24$ & $25-26$ \\
\cline { 2 - 5 } & 3 & 25 & 3 & 1 \\
\hline \multirow{3}{*}{ Class } & Freshmen & Sophomore & Juniors & Seniors \\
\cline { 2 - 5 } & 0 & 1 & 6 & 25 \\
\hline \multirow{2}{*}{ CODO } & Yes & No & \\
\cline { 2 - 5 } & 11 & 21 & \\
\hline \multirow{2}{*}{ Career in Aviation } & Yes & No & \\
\cline { 2 - 5 } & 28 & 4 & \\
\hline \multirow{2}{*}{ Pursuing A\&P } & Yes & & 3 & \\
\cline { 2 - 5 } & 29 & 3 & 3 & \\
\hline
\end{tabular}

While there are a variety of projects to choose from, all students in the overhaul laboratory for the semester were tested using projects with a Federal Aviation Administration defined competency level of 3 . In addition to measuring competency level, the time that each student took to perform the skill was recorded as well as whether they had ever performed the task and when they had last performed the task.

T-Test: A series of t-tests with two-tail distributions and equal variance assumed were performed as an analysis on the data in order to test the hypothesis of this study. The tests can be utilized when there are two sets of data and the sample size is as small as 10 and is not typically used for larger 
sample sizes (Kenton 2018). Since the sample size was 32, a t-test was chosen over other statistical analysis tests.

Conducting this analysis on data allows the data from two separate data sets to be compared. This is helpful in determining if the data came from the same population. The t-test takes a sample from each set and assumes a null hypothesis first. After that, the test is calculated using the mean difference from each data set, the standard deviation of each set, and the number of values of each datasets. The tests compared both time to finish a project in minutes and its result in pass/fail format. Passing grade was recorded as 1, failing in the task as 0 . Each student participated in both scenarios, working with operational and nonoperational engines.

\section{Discussion}

For time to finish, no statistical difference was found between the groups: students performing on operational engines $(M=22.28, S D=14.21)$ and those who worked on nonoperational engines $(M=25.03, S D=15.26), t(62)=-0.75$, $\mathrm{p}=$ n.s.

For results of the tests, no statistical difference was also found between the groups: students performing on operational engines $(M=.84, S D=.37)$ and those who worked on nonoperational engines $(M=.72, S D=.46), t(62)=1.20$, $\mathrm{p}=$ n.s.

Based on those findings, it is possible to claim that there is no difference between preparing and testing the students on both operational and nonoperational engines. This outcome disproves the original hypothesis that equipment operational status would improve students' performance because of the increased pressure to restore the engines to airworthy condition. The data also showed that students took longer on equipment that was not operational. However, the longer amount of time could potentially be caused by the student not being fully focused and mentally relaxed while performing the practical project knowing that the project will make very little to no difference to the operating condition of the engine the student is working on. In order to better understand the current phenomenon, further studies need to be performed.

\section{Conclusions}

Further exploration with additional test data should be done to determine whether a larger sample size would impact the practical project results. Additionally, the researcher should interview the students to gather feedback and gain further understanding regarding the students' experiences testing on operational and nonoperational equipment. The student interviews can possible provide insights as to why there was no statistical relation between equipment operational status and students' technical competency. Further studies are needed in order to determine the cause of the unexpected results. If further 
studies consistently prove that there is no statistical relation between equipment operational status and students' technical competency, this may help training organizations determine that funding for equipment and training might be better allocated elsewhere than ensuring reciprocating engines are operational. Training funding can be spent on cheaper and easier to maintain alternatives such as engine mock-ups.

Since the 1940's, NASA and the US Air Force broadly recognized computer simulation as a preparation tool to reduce errors and decrease associate risks (Gerathewohl 1969, Allerton 2010). In the last eight decades, computer technology has changed drastically. This change has led to an acceptance of the computerbased pilot training as a primary method of preparation from the beginning to certification (Macchiarella et al. 2006). It was also confirmed that computer-based pilot training effectively transfers the positive psychomotor skills (Reweti 2014). Based on those examples, there is an opportunity to use advance simulation technology such as the integration of augmented reality (AR) and virtual reality (VR) into aeronautical engineering preparation and maintenance training. However, further studies are also required to determine the effectiveness of these alternative technologies.

\section{References}

Allerton DJ (2010) The Impact of Flight Simulation in Aerospace. The Aeronautical Journal 114(1162): 747-756.

Behizadeh N (2014) Enacting Problem-Posing Education through Project-Based Learning. English Journal 104(2): 99-104.

Boeing (2018) Pilot and Technician Outlook 2018-2037. Retrieved from https://www.boeing.com/commercial/market/pilot-technician-outlook/.

Federal Aviation Administration (2012) Aviation Mechanic General Practical Test Standards (FAA-S-8081-26A). Retrieved from https://bit.ly/2ErWGJg.

Gerathewohl SJ (1969) Fidelity of Simulation and Transfer of Training: A Review of the Problem. Department of Transportation, Federal Aviation Administration, Office of Aviation Medicine, Washington, DC.

Hwang RH, Hsiung PA, Chen YJ, Lai CF (2017) Innovative Project-Based Learning. Lecture Notes in Computer Science (Including Subseries Lecture Notes in Artificial Intelligence and Lecture Notes in Bioinformatics) 10676, 189-194.

Johnson B, Ulseth R (2017) Student Experience for the Development of Professional Competencies in a Project-Based Learning Curriculum. International Journal of Engineering Education 33(3): 1031-1047.

Kenton W (2018) T-Test Retrieved from https://www.investopedia.com/terms/t/ttest.asp.

Lam SF, Cheng RWY, Choy HC (2010) School Support and Teacher Motivation to Implement Project-Based Learning. Learning and Instruction 20(6): 487-497.

Macchiarella N, Arban P, Doherty S (2006) Transfer of Training from Flight Training Devices to Flight for Ab-initio Pilots. International Journal of Applied Aviation Studies 6(2): 299-314.

Prentice B, Costanza D (2017) Aging Baby Boomers Cause Aircraft Mechanics Shortage as Global Fleet Expands, Modernizes. Retrieved from https://bit.ly/ 2QfODng. 
Rahman E, Mashuri M, Hendikawati P (2017) Project Based Learning Implementation to Improve Students' Problem Solving Ability and Honesty. Unnes Journal of Mathematics Education 6(2): 174-180.

Reweti S (2014) PC-Based Aviation Training Devices for Pilot Training in Visual Flight Rules Procedures; Development, Validation and Effectiveness. Doctoral Dissertation, Massy University, Palmerston North, New Zealand. Retrieved from http://mro.massey.ac.nz/bitstream/handle/10179/5454/02_whole.pdf? sequence=2.

Robinson J (2013) Project-Based Learning: Improving Student Engagement and Performance in the Laboratory. Analytical and Bioanalytical Chemistry 405(1): 7-13. Doi:10.1007/s00216-012-6473-x.

Shin MH (2018) Effects of Project-Based Learning on Students' Motivation and SelfEfficacy. English Teaching 73(1): 95-114.

University of Pittsburgh (2018) Chapter 2 - Purpose of the Human Research Protection Office and Institutional Review Board. Retrieved from https://www. irb.pitt.edu/content/chapter-2-purpose-human-research-protection-office-andinstitutional-review-board.

Walsh A (2018) Senate Addresses Maintenance Tech Shortage. Retrieved from https://www.aopa.org/news-and-media/all-news/2018/march/08/senate-works-toaddress-maintenance-tech-shortage. 